\title{
Anatomy and resilience of the global production ecosystem
}

https://doi.org/10.1038/s41586-019-1712-3

Received: 28 July 2018

Accepted: 23 September 2019

Published online: 6 November 2019

\author{
M. Nyström ${ }^{1 *}$, J.-B. Jouffray ${ }^{1,2}$, A. V. Norström', B. Crona ${ }^{1,2}$, P. Søgaard Jørgensen ${ }^{1,2}$ \\ S. R. Carpenter ${ }^{3}$, Ö. Bodin', V. Galaz ${ }^{1,2}$ \& C. Folke ${ }^{1,2,4}$
}

Much of the Earth's biosphere has been appropriated for the production of harvestable biomass in the form of food, fuel and fibre. Here we show that the simplification and intensification of these systems and their growing connection to international markets has yielded a global production ecosystem that is homogenous, highly connected and characterized by weakened internal feedbacks. We argue that these features converge to yield high and predictable supplies of biomass in the short term, but create conditions for novel and pervasive risks to emerge and interact in the longer term. Steering the global production ecosystem towards a sustainable trajectory will require the redirection of finance, increased transparency and traceability in supply chains, and the participation of a multitude of players, including integrated 'keystone actors' such as multinational corporations.

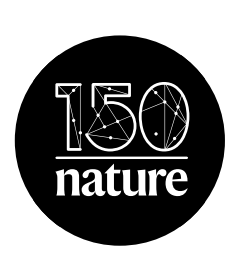

Anniversary collection: go.nature.com/ nature150

The demand for harvestable biomass (food, fuel and fibre) by a growing, wealthier and increasingly urbanized global human population is placing relentless pressure on the Earth's ecosystems. To a large extent, this demand has been met by converting ecosystems into production ecosystems-ecosystems modified for the production of one or a few harvestable species ${ }^{1,2}$. Although these alterations occur at local scales, their cumulative effect is causing global transformation of the Earth's biosphere $^{3,4}$. Humans have already altered more than $75 \%$ of the world's terrestrial habitats ${ }^{5}$-nearly $40 \%$ of all productive land has been converted into agricultural areas ${ }^{6}$ and two thirds of all boreal forests are under some form of management, mainly for wood production ${ }^{7}$. In the seas, around $90 \%$ of large industrial fisheries are either overexploited or fully exploited ${ }^{8}$, and a rapidly expanding aquaculture sector is occupying increasing areas of coastal and offshore space?

As available productive land and abundant fish stocks become progressively scarce, the potential for further land conversion, land redistribution and exploitation of new wild stocks as options to meet projected global human demand is dwindling ${ }^{8,10}$. To increase efficiency, production ecosystems are intensified and simplified using human inputs such as fossil fuels, fertilizers, pesticides, antibiotics and technology ${ }^{2,6,11}$. In parallel, people, places, cultures and economies are increasingly linked across geographic locations and socioeconomic contexts ${ }^{12}$, making production ecosystems increasingly globally interconnected. Collectively, these changes are converting much of the biosphere into a GPE.

This new reality calls for approaches that recognize the biosphere system as a complex and integrated social-ecological system ${ }^{3,13,14}$. Within this context, resilience-the capacity of a system to persist with and adapt to change, but also transform away from unsustainable socialecological trajectories-has been suggested as a conceptual framework that could assist in developing paths towards sustainability ${ }^{15}$. Whereas the aggregated transformation of Earth's biomes is indisputable, its consequences for the dynamics and resilience of an expanding GPE remain poorly understood.

Here we describe the anatomy of the GPE through the lens of three key features underpinning resilience, namely connectivity, diversity and feedback ${ }^{16}$. We do this by considering a diverse set of socioeconomic and biophysical elements that have previously been studied separately. We discuss how this anatomy influences the resilience of the GPE and creates novel conditions for risks to emerge and interact. We conclude by highlighting three avenues that can foster innovation and encourage new partnerships to motivate transformation towards a more sustainable GPE.

\section{The anatomy of the GPE}

The GPE is the result of three important and interacting trends: (1) the continued conversion of the Earth's biosphere into simplified production ecosystems, (2) the increased intensification and dependence of these production ecosystems on human inputs, and (3) their expanding connectivity through global markets. The GPE integrates multiple sectors, broadly referred to here as forestry, agriculture (crops and livestock) and fishery (wild capture and aquaculture) (Fig. 1). We recognize that some production ecosystems, such as subsistence fishing and farming or diversified agricultural landscapes, may be subject to

${ }^{1}$ Stockholm Resilience Centre, Stockholm University, Stockholm, Sweden. ${ }^{2}$ Global Economic Dynamics and the Biosphere Academy Programme, Royal Swedish Academy of Sciences, Stockholm, Sweden. ${ }^{3}$ Center for Limnology, University of Wisconsin-Madison, Madison, WI, USA. ${ }^{4}$ Beijer Institute of Ecological Economics, Royal Swedish Academy of Sciences, Stockholm, Sweden. *e-mail: magnus.nystrom@su.se 


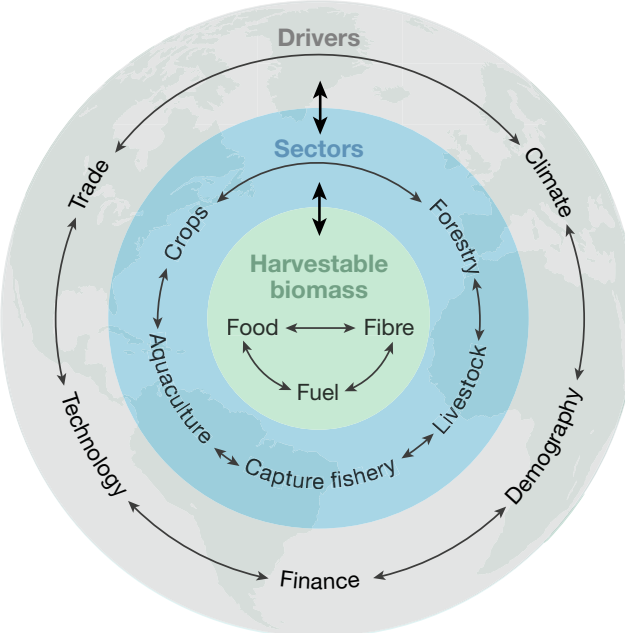

Connectivity: the breakdown of isolation

- Climate connections

- International trade

- Output-as-input relationships

- Transnational corporations

Diversity: more becomes less

- Biotic homogenization

- Habitat simplification

$\downarrow \quad$ - Standardized food supply

- Industry consolidation

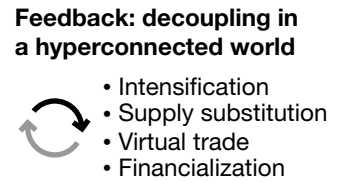

Fig. 1 The global production ecosystem. The GPE is characterized by tightly coupled relationships and reciprocal influence within and between harvestable biomass (green inner circle), multiple sectors (blue middle circle) and a broad set of distal drivers (grey outer circle). To the right are the three lenses (connectivity, diversity and feedback) and their key features through which the anatomy of the GPE is described in this paper. little human input or export-mediated connectivity from international trade. Nevertheless, they will be increasingly shaped by a broader set of global drivers, such as policies, technologies and economic changes ${ }^{2,17}$.

\section{Connectivity: the breakdown of isolation}

A distinctive feature of the present day is the way in which human activities increase connectivity. Although the drivers of this connectivity are not new (for example, trade, transport, technology and consumption), the speed and scale at which it occurs are unprecedented ${ }^{18}$.

Connectivity within the GPE is underpinned by long-distance biophysical and socioeconomic teleconnections ${ }^{12,14}$. For example, irrigation and deforestation for agriculture in one location can redistribute global evapotranspiration, thereby changing rainfall patterns and affecting terrestrial production ecosystems in other regions ${ }^{19}$. Increased $\mathrm{CO}_{2}$ emissions associated with deforestation ${ }^{20}$ also affect aquaculture and wild-capture fisheries through increased seawater temperatures and ocean acidification ${ }^{21}$. Thus, land transformation in one part of the world can have substantial effects on production ecosystems at distant locations, within and across sectors.

At the same time, trade that was once constrained by limitations in transport capacities and lack of trade agreements is increasingly contributing to match global supply and demand ${ }^{22,23}$. International trade has undergone huge expansion in the past few decades ${ }^{24}$, and now accounts for $24 \%$ of all agricultural land ${ }^{25}, 23 \%$ of the freshwater resources used for food production ${ }^{26}$ and more than $35 \%$ of global seafood production ${ }^{8}$. The number of regional trade agreements in force has more than tripled ${ }^{27}$ since 2000 , and nearly all cropland areas brought into production from 1986 to 2009 were used to grow export $\mathrm{crops}^{28}$. As a consequence, production ecosystems have been further simplified and intensified to produce products destined for global markets ${ }^{28-31}$.

The growth of international trade has also increased direct and indirect connections between different production ecosystem sectors. For example, agricultural exports such as soybean and palm oil produced for the European Union, US and Chinese markets are a primary driver of deforestation across the tropics ${ }^{32}$. Sectors have also become intertwined through different output-as-input relationships. Increase in feed trade to satisfy global livestock production is occurring at an unprecedented rate ${ }^{33}$, and as the effects of intensification unfold, new connections are emerging. For instance, the aquaculture sector, which has traditionally relied heavily on capture fisheries as the main source for feed, is shifting towards agriculture for crop-based feed (for example, soy, rapeseed and maize) in response to declining fish catches ${ }^{34}$.
The interconnections between sectors are further amplified by the emergence of large transnational corporations that link production ecosystems globally through their subsidiaries ${ }^{35}$. These vertically and horizontally integrated 'keystone actors' ${ }^{35}$ rely on connectivity for their own growth and represent a critical feature of the GPE by operating across sectors, markets and geographies to source, store, trade, process and distribute biomass. Such integration allows a few actors to dominate all segments of production, control the whole supply chain and have a disproportionate influence on decision-making ${ }^{36}$. Consolidation of large industrial actors has been recorded across many sectors, including forestry, seafood, livestock and agri-food industries ${ }^{37,38}$. There are concerns that such consolidation reinforces global homogenization of species (including genes, varieties and crops), practice and knowledge $\mathrm{e}^{39,40}$.

\section{Diversity: more becomes less}

The purposeful selection of particular harvestable products and the collateral effects of these choices are driving biotic homogenization in both terrestrial and aquatic ecosystems ${ }^{41,42}$. In many areas, boreal forests have been simplified as a consequence of intensive silviculture for timber production ${ }^{7}$, tropical forests have been replaced by spatially extensive monocultures (for example, soy and oil palm plantations) ${ }^{43}$, and native Mediterranean ecosystems have been simplified by exotic pine tree plantations ${ }^{44}$. In grasslands, moderate intensification has resulted in collateral biotic homogenization across microbial, plant and animal groups, both above and below ground ${ }^{45}$. In the Amazon, rainforest bacterial communities have become homogenized as a result of land conversion to cattle pasture ${ }^{46}$ and in marine systems, rising seawater temperatures have led to the rapid homogenization of fish assemblages $^{47}$.

Homogenization is also evident from a food production perspective. More than $80 \%$ of the global fish and shellfish aquaculture production is sourced from 30 species, of which grass carp, silver carp, cupped oysters, common carp and manila clam account for more than $30 \%$ by volume ${ }^{8}$. The pattern is even more striking for the global livestock sector, in which the production of pigs and chicken amount to $40 \%$ and $34 \%$, respectively, of global meat production ${ }^{48}$. In agriculture, national portfolios of food supplies have seen increased crop species diversity, whereas globally they have become more homogeneous in composition, illustrating a shift towards a globally standardized food supply based on a few crop types such as maize, wheat, rice and bar$\mathrm{ley}^{49}$. Homogenization of crop production is further promoted by the 


\section{Perspective}

\section{Box 1}

\section{Financialization of the biosphere}

After decades of financial deregulation and innovation, the intensification of investments in natural assets has led to concerns about the role of an expanding global financial sector in shaping production ecosystems ${ }^{139,140}$. Financialization-defined as the increasing importance of financial markets, motives, institutions and elites in the operation of the economy and its governing institutions ${ }^{141}$ - has been suggested as a rapidly emerging and powerful decoupling mechanism that abstracts biomass from its physical form ${ }^{53}$. For example, new financial practices and instruments, such as securitization and complex commodity derivatives, have led to a situation where only $2 \%$ of commodity futures contracts end with delivery of the physical good ${ }^{93}$. In environmental conservation, financialization is seen as a new frontier for capital investment, in which the responsibility for global environmental outcome is increasingly shifted towards the incentivizing control of investment finance ${ }^{142}$. The green bond market, which is designed to simultaneously achieve financial returns and environmental benefits, has witnessed huge growth over the past five years and is predicted to reach US $\$ 250$ billion in 2019 (Box 1 Figure). Attention is also shifting towards the role of finance within the blue economy narrative ${ }^{143}$. Similar to green bonds, the Seychelles government has announced the world's first blue bond, valued at US $\$ 20$ million to fund sustainable fisheries ${ }^{144}$. However, studies have warned that the growing interest among financial institutions in investments in the seafood sector may lead to adverse effects on small-scale fisheries through increased privatization and ocean grabbing ${ }^{145}$. The use of fishing quotas as collateral in loans by Icelandic banks, and the resulting debt for the industry when the banking system collapsed, provides a compelling example ${ }^{146}$. If financial actors were to become aware of how ecological risks translate into financial risks, entry points for sustainability considerations into financial decisions might emerge with strong incentives to implement better standards and redirect capital towards more sustainable practices ${ }^{113}$. Regardless, financialization of the biosphere should be increasingly recognized and studied as an intrinsic process shaping the GPE.

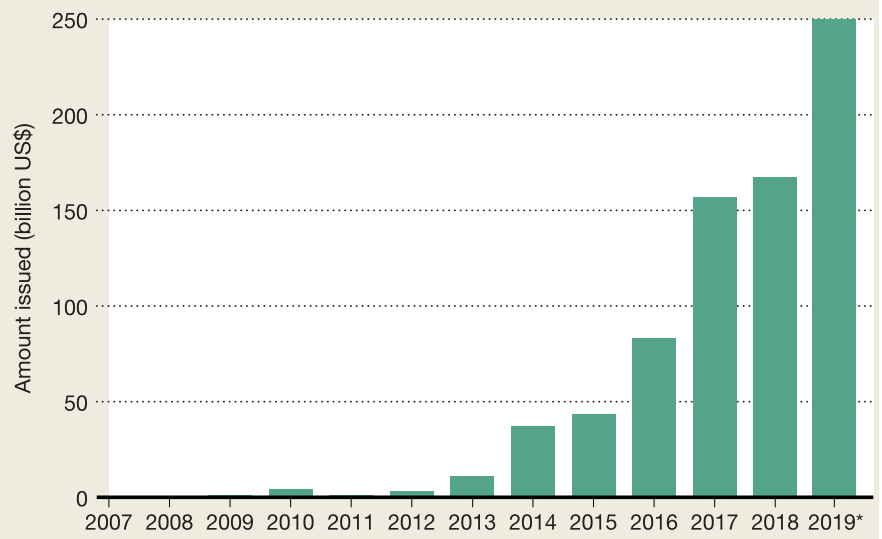

Box 1 Figure | Rise of the global green bond market. Data are from the Climate Bond Initiative (https://www.climatebonds.net). The 2019 data are forecast (indicated by an asterisk). Note that while the growth of the green bond market is unquestionable, it represents only a tiny fraction of the overall bond market, estimated to exceed US $\$ 100$ trillion. recent rise of 'flex crops and commodities ${ }^{\prime 50}$. These are commodities that are suited for multiple uses that can be flexibly interchanged (for example, soy as food for humans, feed for animals, or biofuel; or trees for timber, pulp, ethanol, or carbon sequestration purposes). Such commodities provide flexibility for producers and investors to allocate products depending on which market has the highest demand-for instance, in the face of changes in policy regulations, market prices or technological advances ${ }^{50}$.

\section{Feedback: decoupling in a hyperconnected world}

Paradoxically, increased connectivity within and among production ecosystems is weakening important feedback relationships within the GPE. First, there is broad evidence that intensification decouples production ecosystems from the natural processes needed to sustain desired production outcomes (that is, regulating and supporting ecosystem services) ${ }^{2}$. Instead, human inputs are increasingly used to mimic natural processes and responses in the system. Examples include substituting the natural breakdown and uptake of nutrients (that is, nutrient recycling) with fertilizers to enhance crop productivity, relying on artificial feed inputs to increase aquaculture yield, and replacing natural pest control with pesticides and herbicides to avoid yield losses. This can potentially undermine the capacity of production ecosystems to sustain desired biomass in the long run. For instance, agricultural intensification has been reported to cause soil erosion, declines in fertility, loss of natural pollinators, downstream damage to water resources and degradation of coastal ecosystems ${ }^{38,51}$.

Decoupling also emerges as the geographical distance between the location of biomass production and where it is consumed increases. Approximately one quarter of all food produced for human consumption is traded internationally ${ }^{24}$, and almost one billion people are consuming internationally traded products to cover their daily nutrition $^{52}$. Estimates further suggest that $20 \%$ of global cropland is being allocated to the production of commodities that are consumed in another country ${ }^{31}$. This spatial decoupling, or 'distancing ${ }^{\prime 3}$, allows industries to substitute supplies from different species or production ecosystems so that global consumers remain relatively unaffected by, and unaware of, changes occurring at individual source areas ${ }^{54}$. Declining fish stocks, for example, are compensated for by substituting source areas ${ }^{55}$, shifting to new but similar species ${ }^{54}$ or replacing wild catch with supply from aquaculture ${ }^{30}$. Similarly, international trade enables countries to displace their land use (for example, deforestation) to other nations ${ }^{56}$. As long as consistent demand exists through globally distributed markets, implementation of policies to mitigate overexploitation in one place-such as protected areas or reduced quotas-may simply increase pressure elsewhere (leakage effects), with a global net decline as a result $\mathrm{t}^{10,32}$.

The current global model of biomass production also spatially decouples consumption from the environmental impacts that it entails ${ }^{57}$. These impacts extend beyond direct collateral damages, such as spread of infectious diseases, pollution, habitat degradation and loss of biodiversity. They include reallocation of natural resources (for example, land and water) needed to produce traded commodities destined for direct human consumption or as input to produce biomass with higher protein and nutrient content ${ }^{6,30,38}$. The trade of these embodied resources (virtual trade) has been estimated to incorporate $24 \%$ and $22 \%$ of the global land and water footprint ${ }^{58}$, respectively, and account for $11 \%$ of global groundwater depletion ${ }^{59}$.

More recently, attention has been given to the way in which decoupling may arise from the growing influence of finance and the emergence of novel financial instruments (Box 1). New types of agricultural insurance have been developed whereby payouts are no longer based on direct measured loss of crops, but are instead triggered by an index, such as a predefined threshold in rainfall ${ }^{60}$. Although these index insurance policies present benefits for both insurers (by resolving the problem of moral hazard and reducing the transaction costs of verifying 


\section{A network of networks}

The GPE is a worldwide social-ecological network of networks. It is composed of a large number of interacting networks that span sectoral, jurisdictional and geographical boundaries, connect various actors and institutions, and link human societies to the biosphere. Individual nodes in this global network can represent countries, actors, institutions, sectors, species or ecosystems. Links can capture collaboration, trade, policy overlap, environmental effects, species dispersals or trophic interactions ${ }^{147}$. A networkmodelling approach can help to uncover invaluable clues to the resilience of the GPE. For example, the degrees and patterns of connectivity across the many networks can have important

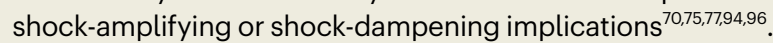

Another promising, but nascent area of research is the investigation of how well social and ecological systems are aligned within a social-ecological network ${ }^{148}$ and empirical assessment of how this social-ecological fit affects outcomes in the system ${ }^{149}$. For example, early results suggest that high levels of social-ecological fit provide an important foundation for more sustainable and adaptive practices to emerge ${ }^{150}$ (Box 2 Figure). Future research should aim at exploring the nature and extent of social-ecological fit in the GPE, but also whether enhancing social-ecological fit could lead to mechanisms that unravel and expose different masking effects, such as land displacement, sequential overexploitation and virtual trade.

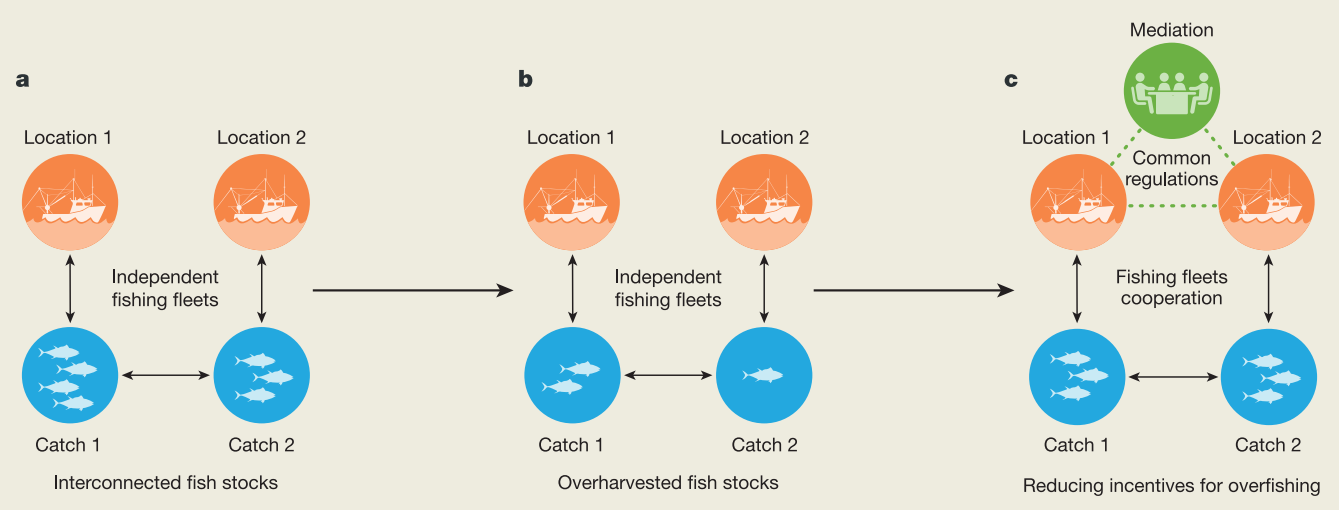

\section{Box 2 Figure | Enhanciological fit in fisheries.}

a-c, The blue nodes represent interconnected fish stocks (for example, through dispersal and seasonal migration) being targeted at different locations by different fishing fleets (red nodes). For highly mobile fish species such as tuna, the distance between any two localized stocks can be very large and cross several jurisdictional borders. a, If actors (fishing fleets) are operating independently of each other, the ecological and social connectivities are not aligned. This makes it more difficult to respond collectively to changes and disturbances, and can incentivize actors to (knowingly or unknowingly) overharvest fish stocks. b, Overfishing in one location will negatively affect the status of the fish stock in the other location, and vice versa.

losses) and farmers (by improving access to credit and mitigating climate risk), they are often coupled to the adoption of commercial inputs and specific crops that reinforce the simplification of agricultural landscapes and the homogenization of practices. This increases smallholders' exposure to risks and erodes their ability to adapt to extreme environmental variability ${ }^{60}$. Because the actual agricultural performance is no longer relevant for the indemnity payment, farmers are also at risk of experiencing losses but not receiving a payment if the index threshold is not met.

Collectively, these different decoupling mechanisms have ramifications for how production ecosystems and the benefits they produce are perceived, valued and managed ${ }^{13,61}$.

\section{Resilience in the GPE}

Resilience is a concept that is widely used in science, management and policy. The concept has multiple meanings, which can have consequences for evaluating, understanding, and managing systems, c, Bringing the actors closer together (for example, through exchanging information or agreeing on common regulations) would increase the possibilities for tightening social-ecological feedback loops (recoupling), thus reducing incentives for overfishing ${ }^{149}$ and increasing the likelihood of the emergence of collective action ${ }^{147}$. Such increased social-ecological fit could be established either by connecting the different actors directly, or indirectly through a third-party mediator. Examples of direct connections include the emergence of fishing collectives ${ }^{151}$ or cooperation among global seafood companies ${ }^{132}$. An indirect connection could occur through a regional fishery management organization, in which the participating member states adhere to commonly devised fishery regulations for stocks over which no single state has full authority.

depending on which definition is used. Resilience can refer to the time it takes for a system to return to its original state after perturbation (recovery) or, as in this Perspective, it can describe the extent to which a system can develop with change by absorbing recurrent perturbations, deal with uncertainty and risk, and still sustain its key properties ${ }^{15}$, such as the capacity to feed humanity in the case of the GPE. Concerns have been raised that the profound human influence on the biosphere is eroding resilience and causing abrupt changes in social, ecological and social-ecological systems ${ }^{62,63}$. These 'regime shifts' may interact and cascade $^{64}$, thereby producing change at very large scales with severe implications for the wellbeing of human societies ${ }^{65}$. Since the GPE has become a substantial part of the biosphere, investigation of what a hyperconnected, homogenized and decoupled anatomy means for its resilience is urgently needed.

\section{The structure of fragility}

Analysing systems as networks that consist of nodes and links has proved to be a fertile ground for exploring the relationship between 


\section{Perspective}

a Local low-intensity production ecosystem

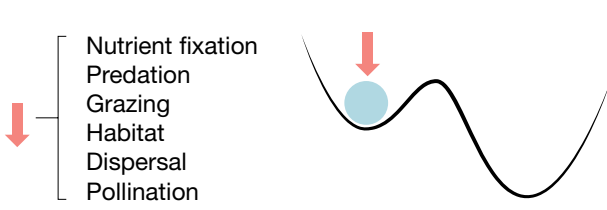

Pollination

b

Local high-intensity production ecosystem

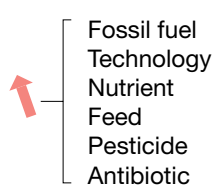

Antibiotic

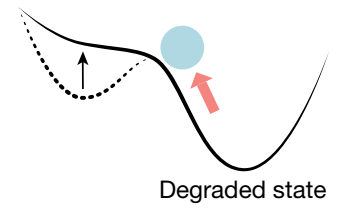

C Global production ecosystem

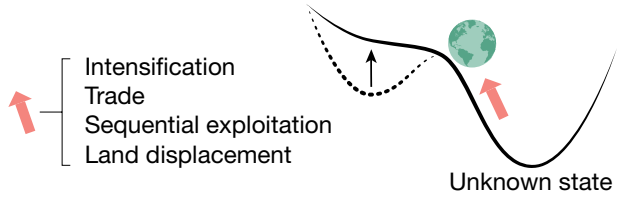

Fig. 2 | Masking loss of resilience. a, The state of a local low-intensity production ecosystem (blue dot) is maintained by a suite of biophysical processes (red arrow). Variability in environmental conditions creates fluctuations in biomass output (blue bars). This variability may not be an acceptable solution as drops in the production may not sufficiently meet the needs of people depending on it. b, A local high-intensity production ecosystem is kept in a forced state by continuously adding anthropogenic inputs, such as increasing use of antibiotics to avoid diseases in aquaculture and livestock, and herbicides to prevent weeds in crop systems. Intensification increases productivity and suppresses fluctuations in harvestable biomass in the short term (blue bars). This occurs at the expense of eroding resilience in
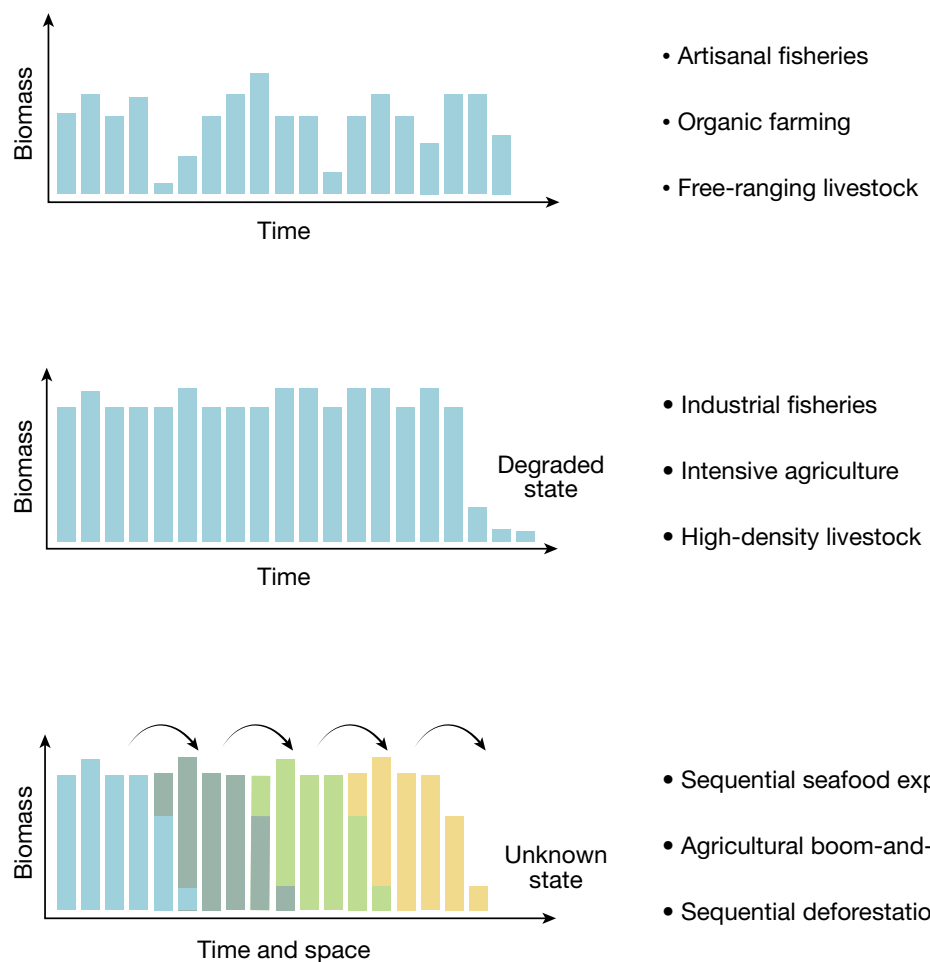

- Sequential seafood exploitation

- Agricultural boom-and-bust

- Sequential deforestation structure and resilience in ecological ${ }^{66,67}$, financial ${ }^{68-70}$, technologi$\mathrm{cal}^{71,72}$ and climatic systems ${ }^{73}$. Depending on how nodes are organized, connectivity can increase or decrease the resilience in a network ${ }^{74}$. A recent empirical reconstruction of the global food trade network from 1986 to 2013 showed that it displays characteristics of a heterogeneous network in which countries have many incoming (import) and few outgoing (export) connections, or vice versa ${ }^{74}$. The study also found that the food system has become progressively delocalized as a result of globalization (that is, modularity has been reduced). Combining these properties, the authors concluded that resilience in the global food network has declined over the past 20 years and that addition of new trade routes to this heterogeneity will further erode resilience ${ }^{74}$.

Another important line of research focuses on the interaction between connectivity and diversity in the network (that is, how nodes are different from each other $)^{75}$. Studies suggest that, in systems in which the diversity of responses among nodes is high and connectivity between them is low, the systemic response to perturbation is gradual. By contrast, if nodes are homogeneous and highly connected, their responses become more synchronized ${ }^{70,75-77}$. The global financial crisis provides an illustrative example in which a small number of tightly connected banks deployed similar risk-management models, thus cultivating homogeneity at the global scale and paving the way for shocks to propagate throughout the financial system ${ }^{68}$. Connectivity and diversity therefore determine whether a system has a shock-dampening or a shock-amplifying effect when exposed to perturbations ${ }^{77}$. Linking the long term (dashed line and black arrow), which increases the risk of surpassing a threshold beyond which the system may fall into a degraded state, precipitating a collapse of biomass.c. Similarly, the GPE (represented by the Earth) is kept in a forced state through intensification, trade and spatial displacement of activities (red arrow), to maintain a high and predictable global supply of biomass arriving from different stocks, species, geographic locations (multi-coloured bars). Loss of resilience (dashed line and black arrow) is masked at a global level, thus increasing the risk of shifting the GPE into an unknown state. To the right are systems within which examples of the illustrated dynamics can be found (see Supplementary Table1).

networks together can help to reduce pressure in individual networks, but may occur at the expense of increasing fragility of the broader interconnected network ${ }^{71}$. Indeed, studies in power-communication ${ }^{72}$, financial ${ }^{68}$ and ecological ${ }^{64}$ systems have shown that a large interconnected 'network of networks' can be intrinsically more fragile than each network in isolation.

In the GPE, intensification and globalization have produced strong interdependencies within and among sectors. In parallel, homogenization has reduced the diversity of ways in which species, people, sectors and institutions can respond to change (loss of response diversity) ${ }^{78}$ as well as their potential to functionally complement each other (loss of redundancy $)^{16,79}$. This suggests that the GPE possesses features that could amplify shocks ${ }^{80}$. Understanding such potential shock-amplifying behaviour will require a better evaluation of how ecological, social and social-ecological connectivity and diversity interact (Box 2).

\section{Masking loss of resilience}

Fluctuations in harvestable biomass outputs influence producer income and undermine the continued and stable supply to consumers (Fig. 2a). Strategies that reduce this variation to improve efficiency and predictability are therefore frequently sought. However, enhanced short-term control can have implications for resilience in the long term.

Increasing variability (variance) can be a signal of declining resilience in complex systems, including ecosystems and social-ecological systems $^{75}$ (but see ref. ${ }^{81}$ ). Hence, intensification strategies that deliberately 


\section{Linking anatomy to resilience: empirical examples from food production}

The resilience of a given system depends on the interplay between exogenous (external) forces and the endogenous (internal) properties of the system (Box 3 Figure). There is growing evidence that key external and internal dynamics of the GPE have been altered to the extent that they are compromising its resilience. Here we consider and empirically illustrate two examples of such dynamics.

\section{Altered perturbations and increasing food-shock frequency} As connectivity and homogeneity increase, shocks within a more prevalent ${ }^{97}$. Major drivers of these shocks include extreme weather events, spread of disease and geopolitical or economic conflicts, although their relative importance can differ across regions. For instance, droughts and floods have been particularly dominant forces of sudden declines in crop production over the past decades in South Asia, whereas geopolitical and economic crises are leading drivers of agricultural shocks in sub-Saharan Africa ${ }^{80}$. Furthermore, geopolitical and economic events-such as withdrawal of subsidies, reduced export markets and internal conflicts-tend to generate shocks that span multiple sectors across both land and sea ${ }^{80}$. Importantly, despite efforts to maintain high yields, food production shocks have become more frequent over the past 50 years (Box 3 Fig. a). These shocks pose a threat to food geographic area or sector can become globally contagious and

security and the resilience of the global food system through price volatilities and effects on trade ${ }^{80}$.

\section{The looming threat of herbicide resistance}

Homogenization towards pesticide-intensive production practices in agroecosystems has increased selection for pesticide resistance and reduced the resilience of the GPE to pests and pathogens ${ }^{137}$. For instance, according to The International Survey of Herbicide Resistant Weeds (www.weedscience.org), as of 2019, weeds have evolved resistance to 167 different herbicides and to 23 of the 26 known herbicide sites of action. Glyphosate is currently the most commonly applied weedkiller, accounting for approximately twothirds of all herbicide use globally. First introduced in 1974, the application of glyphosate began to escalate in the mid-1990s with the rapid adoption of glyphosate-resistant transgenic crops, which enabled farmers to use glyphosate liberally as a strategy to maintain and enhance yields (Box 3 Fig. b). However, such short-term damping of variability can erode resilience in the long term ${ }^{82}$. The overreliance on glyphosate rapidly accelerated the evolution and spread of glyphosate-resistant weeds across all major economies (Box 3 Fig. b), ultimately creating conditions for a looming global failure of weed management ${ }^{138}$.

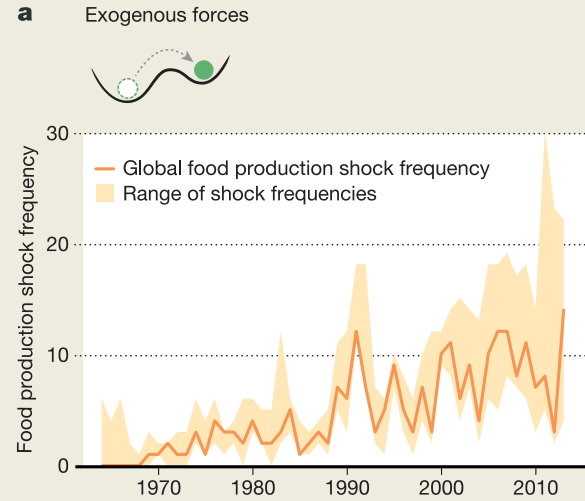

Box 3 Figure | Linking anatomy to resilience. a, b, The schematic of the stability landscape illustrates two ways by which exogenous forces (a) and changes in endogenous system properties (b) can lead to state shifts (dashed arrows) in food production systems.

a, The annual increase in global food production shock frequency, including fisheries, aquaculture, crop and livestock sectors.

suppress variance may remove a useful warning of declining resilience in production ecosystems, sectors and the broader $\mathrm{GPE}^{82}$. Variance is often suppressed by controlling stress and stochastic perturbations such as grazing, fire and pest outbreaks. Such events have been proposed to increase system resilience in the long term by selecting for particular tolerant genes, species traits or practices ${ }^{83,84}$. Therefore, preventing these events may gradually erode resilience, making systems more vulnerable to disturbances that could previously be absorbed. Suppressing short-term variance can also lead to an accumulation of variance in the longer term ${ }^{82}$. As variance accumulates, more force b Endogenous properties

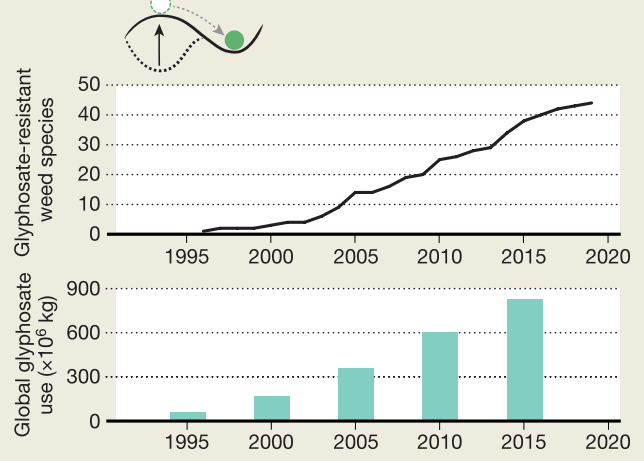

The confidence interval (orange shaded region) represents the range of plausible shock frequencies under different model parameters used for shock detection ${ }^{80} . \mathbf{b}$, The growing number of glyphosate-resistant weeds (black line) as global glyphosate use (blue bars) increases. See Supplementary Note 1 for methodology and data sources. (that is, human input) is required to maintain the system in a desired state (Fig. 2b). Resilience under such conditions has been described as 'coerced' ${ }^{2}$. In forest production ecosystems, for example, stochastic wildfires are often curbed to maintain high and stable yields of harvestable biomass. However, small-scale fires have an important role in reducing the accumulation of dead wood and creating a heterogeneity of patches with less-flammable species that reduces the risk of ignition and prevents fires from propagating ${ }^{85,86}$. This allows the system to suffer fire without eminent risk of crossing a critical threshold whereby it becomes catastrophic and uncontrollable. By contrast, when 


\section{Perspective}

small-scale wildfires are suppressed, homogeneity increases and the amount of wood fuel piles up. This creates a situation in which a single ignition could potentially set the whole forest on fire. If a catastrophic fire unfolds, it can start to interact with the atmosphere and generate convection-driven winds, which further increase its size, spread and speed, making the fire unstoppable ${ }^{85}$. Consequently, management aimed at controlling short-term variability breeds systemic vulnerability in the long $\operatorname{run}^{82}$ (Box 3 ).

The anatomy of the GPE provides for spatial suppression of and accumulation of variance at a global level because components of the system (for example, sectors, places and stocks) are often viewed and governed in isolation (Fig. 2c). This global coercion of resilience is facilitated by sequential exploitation and displacement of activities. For example, countries transitioning from net deforestation to net reforestation may do so through geographic substitution ${ }^{87}$. In Vietnam, forest cover increase was achieved at the expense of deforestation in neighbouring countries such as Cambodia and $\operatorname{Laos}^{56}$. Similarly, following the collapse of the North Sea cod (Gadus morhua) population, UK imports shifted to Atlantic cod sourced from Iceland and the Faeroes, leaving UK consumers relatively unaffected and unaware ${ }^{54}$. Such decoupling mechanisms could explain why national supply stability tends to increase as countries' reliance on trade grows ${ }^{88}$, although it may contribute to global instability in the long term ${ }^{74}$.

\section{Altered disturbance landscape and systemic risks}

Resilience management has generally focused on local systems and their capacity to deal with a narrow range of well-known shocks ${ }^{89}$, such as drought, fire, pest outbreaks and, increasingly, climate change. However, perturbations that previously had only minor or no effects on a certain production ecosystem may suddenly become significant as sectors are progressively intensified and intertwined. For example, droughts or crop pest outbreaks may cause disruption in seafood production, as the aquaculture sector is now dependent on agriculture for crop feeds ${ }^{30}$. Moreover, the GPE has become increasingly exposed to price fluctuation in inputs (for example, fossil fuels, fertilizers and technology) ${ }^{90}$, shifts in global consumer preferences (for example, diets) ${ }^{91}$, changes in policies (for example, regulations on energy and exports) ${ }^{92}$ and speculation on food commodities ${ }^{93}$. Concerns have also been raised about the vulnerability of the infrastructure network on which trade of biomass relies, such as choke points in maritime transportation, which could generate significant instabilities if disrupted ${ }^{90,94}$.

As connectivity and homogeneity increase, shocks that were previously contained within a geographic area or a sector are becoming globally contagious and more prevalent (Box 3 ). For example, protectionist trade strategies, such as implementation of export bans following droughts to protect populations in producing countries, can affect nations that rely on trade to balance their food needs ${ }^{52,95}$. Interest in these types of interconnected risks has increased in recent years along with the terminology to describe them, including nested and teleconnected vulnerabilities ${ }^{12}$, hyper-risks ${ }^{76}$, femtorisks ${ }^{96}$, global systemic risks ${ }^{94}$ and Anthropocene risk ${ }^{97}$. They stem from interactions at the interface of multiple systems (for example, climatic, ecological, political, financial and technological), making causal links opaque and outcomes difficult to foresee $^{76}$.

Despite the inherent uncertainties, this broad spectrum of perturbations and interconnected shocks must be considered to adequately manage resilience in the GPE. It also suggests that the limits of the GPE in satisfying demands for harvestable biomass may be set by the potential consequences of these emergent risks, as opposed to hard upper limits to production per se. The future will require confronting risks that we know little about ${ }^{89,98}$, such as the consequences of an expanding global financial sector (Box 1) and new technologies, including the growth of genetic engineering and synthetic biology ${ }^{42}$. It will also entail accounting for interactions with non-biomass producing sectors that, for instance, support critical infrastructure or energy supply.
Competition between production sectors for land and resources (most importantly water) is indeed likely to intensify as demand continues to grow and effects of climate change unfold.

\section{Towards a sustainable GPE}

Providing a growing human population with food, fibre and fuel in a sustainable and fair way is one of the grand challenges facing humanity. Although the GPE has offered huge benefits by increasing the production of certain desired species ${ }^{99}$, the intensification and simplification of production ecosystems have been criticized from ecological ${ }^{2,6,11}$, social $^{17,39}$ and social-ecological perspectives ${ }^{100}$. Consequently, we argue that it should be substantially and deliberately transformed towards a sustainable trajectory, on which: (1) the demands for biomass are met in a fair and just way, without undermining the functioning of the biosphere, (2) connectivity is capitalized on to improve sustainability, (3) biological and social diversity is enhanced to ensure building blocks for adaptability and transformation in the face of change, and (4) feedback loops are strengthened (recoupled) to avoid masking effects and coercion of resilience.

Determining the boundary conditions characterizing a sustainable GPE is a challenging task that will involve a mix of approaches. The planetary boundaries framework ${ }^{101}$ can be used to define global and regional limits in biophysical processes-the 'safe operating environmental space'-that must not be transgressed if humanity is to stay away from systemic and potentially irreversible shifts in the biosphere. For example, this framework was recently applied to quantitatively estimate how to keep the global food system within environmental limits ${ }^{102}$. Combined with the aspirational social goals framework ('safe and just space for humanity') ${ }^{103}$, this can provide a starting point for discussions around levels of acceptable risk and trade-offs between productivity, sustainability and equity ${ }^{104}$.

Steering the GPE towards a sustainable trajectory will also require a combination of more specific strategies and solutions, as well as careful consideration of their feasibility and the trade-offs involved. Although the polarized debate between the integration (land sharing) and separation (land sparing) of conservation and production fits into discussions around food production and land scarcity, it is ill-suited to address issues of scale (for example, temporal variation in agricultural land use patterns and total area for conservation) or effects of globalization (for example, displacement activities) ${ }^{105}$. The land-sparing versus landsharing debate is too often framed as a binary choice, ignoring possible middle ground and cross-fertilization. Within this context, sustainable intensification has gained momentum in discussions around global sustainability and has become a policy goal for many institutions to deliver on global social and environmental commitments (for example, the UN Sustainable Development Goals and the Paris Agreement). However, it has also been criticized for having a narrow focus on efficiency gains and technological interventions ${ }^{106}$. More systemic forms of sustainable intensification have therefore begun to occur at large scales and across a wide range of agroecosystems, to redesign the composition and structure of production ecosystems and harness a broad range of ecological processes such as predation, parasitism, herbivory, nitrogen fixation and pollination ${ }^{107}$. Further efforts towards a sustainable GPE include approaches to ensure more stable food supplies by increasing national crop diversity ${ }^{108}$, broad-scale shifts in diets and strategies to reduce loss and waste of biomass ${ }^{102}$, and the integration of local realities and contexts, such as procedural justice and equitable distribution of benefits from multi-functional land and seascapes ${ }^{17,109}$.

Although these initiatives are contributing to sustainability in important ways, they are being challenged by an expanding GPE in which systemic, sectoral and jurisdictional boundaries are increasingly blurred. Acting on this new reality entails creating conditions that foster innovation, incentivize transformation and encourage new partnerships across different sectors and actor groups ${ }^{110}$. For this reason, we 
propose three entry points towards a more sustainable GPE that have great transformative potential but are still in their infancy.

\section{Redirecting finance for sustainability}

Financial investments-public or private-are increasingly recognized as key leverage points for achieving sustainability ${ }^{111-113}$. Government subsidies channel large amounts of public capital into the different sectors of the GPE, ultimately influencing practices and species production on the ground. Whereas subsidies have mostly been associated with unsustainable practices, such as fuelling over-capacity in the fishing industry ${ }^{114}$, they could also provide powerful incentives for improved sustainability if linked to the right criteria. In the European Union's reformed Common Agricultural Policy, for example, a direct payment scheme is used to incentivize sustainable resource management, in which farmers who comply with greening measures (that is, addressing biodiversity loss, avoiding crop monoculture and securing carbon sequestration) benefit financially from payments (but see ref. ${ }^{115}$ ). Another recent government-led action is the alliance of Central Banks and Supervisors Network for Greening the Financial System (NGFS), formed during the One Planet Summit in 2017 to explore the role of and possibilities for central banks to use their mandate to incentivize economies to transition to more sustainable pathways ${ }^{116}$.

Private financial actors such as asset managers and commercial banks channel the bulk of capital behind the expansion of the GPE by investing in or lending to companies in different production sectors. Although direct causality between financial flows and environmental change is often opaque ${ }^{112,117}$, such investments represent a potential source of influence over corporate practices. Shareholders of publicly listed companies have the ability to affect a firm's sustainability performance by exercising their voting rights at shareholder meetings (shareholder activism). They can engage directly with the corporate leadership on governance and policy, or indirectly through chains of ownership and threats of divestment. For example, the world's largest sovereign wealth fund-Norway's Government Pension Fund-has divested from 32 companies involved in unsustainable palm oil production since deforestation became an ethical criterion in 2012 (https://www.nbim.no). The insurance sector could also provide important leverage towards more sustainable practices-for instance, by refusing to insure fishing vessels associated with illegal, unreported and unregulated fishing ${ }^{118}$. Similarly, loan covenants (that is, the specific conditions associated with credit lending) provide a powerful tool for banks to influence the behaviour of borrowing companies operating in the GPE by denying access to clients that do not comply with sustainability standards and providing incentives so that better sustainability performance results in reduced interest rates ${ }^{113}$. In this context, pressure from governments and finance ministries will be essential to promote new norms and regulations that can align banks, financial markets and other investors with sustainability goals ${ }^{113}$.

\section{Radical transparency and traceability}

Consumers can be influential in promoting sustainability by aligning their purchasing with sustainable thinking. They are also important as citizens whose perceptions and opinions drive the political will to address sustainability issues. Education and provision of informationsuch as certification, labelling schemes and public campaigns-are therefore central instruments for consumers to make informed decisions $^{54}$. However, if as a society we do not know where, how, in what quantity and by whom a given commodity is produced, it is arguably difficult to tackle sustainability challenges ${ }^{119}$.

Whereas transparency is necessary to assess the environmental sustainability of corporate and financial activities, traceability represents a key mechanism by which corporations can ensure that their supply chains are devoid of unacceptable behaviour, ranging from illegal sourcing and forced labour to poor sanitation and mislabelling $^{120-122}$. Many of the operations of the corporate and financial world are still plagued by opaqueness ${ }^{119,123}$, including secrecy around financial transactions and corporate loans ${ }^{117}$, as well as poor disclosure on implementation of corporate policy and internal allocation of capital (see https://www.ifrs.org/).

Radical transparency and traceability require the disclosure of production volumes and practices. It also demands that corporate and governmental policies are put in place to ensure that social and environmental criteria are met in all supply chain segments, as well as mechanisms to monitor how such regulations are implemented and enforced $^{124,125}$. To date, improved corporate disclosure has largely been driven by voluntary action ${ }^{125}$ under the scrutiny of non-governmental organizations (NGOs). Whereas the Global Reporting Initiative (https:// www.globalreporting.org) is a prominent example of widely adopted sustainability reporting standards, the more recent World Benchmarking Alliance (https://www.worldbenchmarkingalliance.org/) encourages companies to disclose information that allows evaluation of their operations in relation to industry benchmarks. Even though mandatory reporting is increasing globally, limited regulation contributes to poor transparency and sustainability-related corporate reporting remains voluntary in many jurisdictions (see https://www.carrotsandsticks. net). More stringent and clearly articulated criteria for disclosure therefore represent an important step towards more transparent corporate practices.

Emerging digital technologies that deliver decentralized systems, such as blockchain ${ }^{126,127}$, could resolve some of these issues and improve traceability in the GPE. However, these technologies are energy-intensive and interoperability remains a hurdle because seamless communication between digital platforms and agreed-on data for transmission are largely unrealized ${ }^{128}$. Thus, barriers to chain-wide traceability are not just technological but also organizational, and will require changes in legislation and the institutions that govern trade to stimulate cooperation throughout supply chains ${ }^{124}$.

\section{Keystone actors as global agents of change}

A key facet of sustainability science is that the identification of challenges and their solutions requires collaboration between researchers and actors from outside academia ${ }^{129}$. Generally, these actors encompass local communities, indigenous groups, management agencies, NGOs and government actors. More recently, however, increasing attention has been directed towards large transnational corporations and their role as a threat to, or as an opportunity for, sustainable transformation $37,130,131$.

Private governance raises concerns associated with accountability, fair representation and global equity ${ }^{36}$. Nevertheless, transnational corporations have become a central feature of the GPE (that is, keystone actors), with a capacity to influence practices across supply chains and geographical locations ${ }^{35}$, and thus have the potential to become powerful agents of change for improved sustainability ${ }^{37}$. An increasing number of private sector initiatives is emerging with the intention to mobilize companies to take tangible actions, make investments and form partnerships to deliver on sustainability ${ }^{37}$.

Scientists have an important role to play in this context, acting as independent knowledge brokers to ensure that the agendas of keystone actors are based on scientific evidence and align with long-term sustainability goals. Seafood Business for Ocean Stewardship (SeaBOS) provides an unconventional example of a co-production initiative in which scientists directly engaged with the world's largest seafood companies to stimulate transformative change towards improved ocean stewardship ${ }^{132}$. Drawing on an empirical identification of the largest companies involved in aquaculture and wild-capture fisheries ${ }^{35}$ this global science-business initiative emerged in 2016 with a number of task forces led by member companies in collaboration with and supported by scientists (https://www.keystonedialogues.earth). While the long-term outcome remains to be evaluated, the 10 companies engaged in SeaBOS can influence the strategic direction of more than 600 subsidiaries with operations in at least 90 different countries ${ }^{132}$. 


\section{Perspective}

Although this presents a promising approach to be replicated in other sectors in the GPE, such engagements do not come without risk. For scientists, they may cause reputational damage and loss of credibility if companies use the initiative for greenwashing purposes or if they fall short on their promises. For the private sector, they may lead to competitive disadvantage and loss of profit in the short term if other companies do not participate. Nevertheless, with renewable biomass and global sustainability at stake, there are strong incentives for novel science-business partnerships to emerge in combination with effective public policies and improved governmental regulations ${ }^{37}$.

\section{Conclusion}

The rate of change of the Earth's system is accelerating. Unless meaningful actions are taken within the next decade, we will almost certainly face a changed and increasingly unstable climate regime ${ }^{65}$, with serious disruptions to the GPE as a consequence. The current GPE is itself a major driver of this change, accounting for nearly a quarter of all anthropogenic greenhouse gas emissions over the past decade ${ }^{133}$. As a result, agriculture, forestry and fishing are increasingly embedded in international efforts to tackle climate change. Government policies are essential to foster such transformations and align the global economy with sustainability goals. In the face of the urgency and complexity of this challenge, we also need to explore new spaces for innovation and transformation. Although the avenues proposed here are in their infancy, they provide potential entry points for transformative change and a complement to effective governmental regulations. Ultimately, moving towards a more sustainable GPE is likely to require radical shifts in deeply held values, education systems and social behaviour that underpin current economic paradigms, consumption patterns and power relationships ${ }^{134-136}$. Scientists have an important role to play in this process.

1. Bennett, E. M. \& Balvanera, P. The future of SMEs in a globalized world. Front. Ecol. Environ. 5, 191-198 (2007)

2. Rist, L. et al. Applying resilience thinking to production ecosystems. Ecosphere 5, 1-11 (2014).

This study shows how anthropogenic inputs of external resources can lead to a 'coercion' of resilience and how the global connectivity among production ecosystems can obscure signals indicating resilience loss.

3. Vitousek, P. M., Mooney, H. A., Lubchenco, J. \& Melillo, J. M. Human domination of Earth's ecosystems. Science 277, 494-499 (1997).

4. Barnosky, A. D. et al. Approaching a state shift in Earth's biosphere. Nature 486, 52-58 (2012).

5. Ellis, E. C. Anthropogenic transformation of the terrestrial biosphere. Philos. Trans. R. Soc. A 369, 1010-1035 (2011).

The paper shows how humans have transformed the biosphere into intensified anthropogenic biomes over the past century.

6. Foley, J. A. et al. Solutions for a cultivated planet. Nature 478, 337-342 (2011).

7. Gauthier, S., Bernier, P., Kuuluvainen, T., Shvidenko, A. Z. \& Schepaschenko, D. G. Boreal forest health and global change. Science 349, 819-822 (2015)

8. The State of World Fisheries and Aquaculture 2018-Meeting the Sustainable Development (FAO, 2018).

9. Lester, S. E. et al. Marine spatial planning makes room for offshore aquaculture in crowded coastal waters. Nat. Commun. 9, 945 (2018).

10. Lambin, E. F. \& Meyfroidt, P. Global land use change, economic globalization, and the looming land scarcity. Proc. Natl Acad. Sci. USA 108, 3465-3472 (2011).

11. Tilman, D., Cassman, K. G., Matson, P. A., Naylor, R. \& Polasky, S. Agricultural sustainability and intensive production practices. Nature 418, 671-677 (2002).

12. Adger, W. N. Eakin, H. \& Winkels, A. Nested and teleconnected vulnerabilities to environmental change. Front. Ecol. Environ. 7, 150-157 (2009)

13. Folke, C. et al. Reconnecting to the biosphere. Ambio 40, 719-738 (2011)

14. Liu, J. et al. Systems integration for global sustainability. Science 347, 1258832 (2015) This paper suggests ways forward for improved integration of distal human and natural components to address global sustainability

15. Folke, C. et al. Social-ecological resilience and biosphere-based sustainability science. Ecol. Soc. 21, art41 (2016).

This work shows how resilience can be used as a lens to understand social-ecological systems and to address biosphere-based sustainability.

16. Biggs, R. et al. Toward principles for enhancing the resilience of ecosystem services. Annu. Rev. Environ. Resour. 37, 421-448 (2012).

17. Fischer, J., Meacham, M. \& Queiroz, C. A plea for multifunctional landscapes. Front. Ecol. Environ. 15, 59 (2017)

18. Steffen, W., Broadgate, W., Deutsch, L., Gaffney, O. \& Ludwig, C. The trajectory of the Anthropocene: the Great Acceleration. Anthr. Rev. 2, 81-98 (2015).
19. de Vrese, P., Hagemann, S. \& Claussen, M. Asian irrigation, African rain: remote impacts of irrigation. Geophys. Res. Lett. 43, 3737-3745 (2016)

20. Bonan, G. B. Forests and climate change: forcings, feedbacks, and the climate benefits of forests. Science 320, 1444-1449 (2008).

21. Barange, M. et al. Impacts of Climate Change on Fisheries and Aquaculture: Synthesis of Current Knowledge, Adaptation and Mitigation Options (FAO, 2018).

22. Anderson, K. Globalization's effects on world agricultural trade, 1960-2050. Philos. Trans. R. Soc. Lond. B 365, 3007-3021 (2010).

23. Marchand, P. et al. Reserves and trade jointly determine exposure to food supply shocks. Environ. Res. Lett. 11, 095009 (2016).

24. D'Odorico, P., Carr, J. A., Laio, F., Ridolfi, L. \& Vandoni, S. Feeding humanity through global food trade. Earth's Future 2, 458-469 (2014).

25. Weinzettel, J., Hertwich, E. G., Peters, G. P., Steen-Olsen, K. \& Galli, A. Affluence drives the global displacement of land use. Glob. Environ. Change 23, 433-438 (2013)

26. D'Odorico, P. \& Rulli, M. C. The fourth food revolution. Nat. Geosci. 6, 417-418 (2013).

27. Regional Trade Agreements Information System Database (WTO, accessed 14 May 2018); https://rtais.wto.org/Ul/PublicMaintainRTAHome.aspx.

28. Kastner, T., Erb, K. H. \& Haberl, H. Rapid growth in agricultural trade: Effects on global area efficiency and the role of management. Environ. Res. Lett. 9, 034015 (2014).

29. Rudel, T. K. et al. Agricultural intensification and changes in cultivated areas, 1970-2005. Proc. Natl Acad. Sci. USA 106, 20675-20680 (2009).

30. Troell, M. et al. Does aquaculture add resilience to the global food system? Proc. Natl Acad. Sci. USA 111, 13257-13263 (2014).

31. MacDonald, G. K. et al. Rethinking agricultural trade relationships in an era of globalization. Bioscience 65, 275-289 (2015).

32. Fuchs, R. et al. Why the US-China trade war spells disaster for the Amazon. Nature 567, 451-454 (2019).

33. Galloway, J. N. et al. International trade in meat: the tip of the pork chop. Ambio 36 622-629 (2007).

34. Fry, J. P. et al. Environmental health impacts of feeding crops to farmed fish. Environ. Int. 91, 201-214 (2016)

35. Österblom, $\mathrm{H}$. et al. Transnational corporations as 'keystone actors' in marine ecosystems. PLoS ONE 10, e0127533 (2015).

36. Clapp, J. \& Fuchs, D. A. (eds) Corporate Power in Global Agrifood Governance (MIT Press, 2009).

37. Folke, C. et al. Transnational corporations and the challenge of biosphere stewardship. Nat. Ecol. Evol. 3, 1396-1403 (2019).

38. Naylor, R. et al. Losing the links between livestock and land. Science 310, 1621-1622 (2005).

39. Hendrickson, M. K. Resilience in a concentrated and consolidated food system. J. Environ. Stud. Sci. 5, 418-431 (2015)

40. Jefferson, O. A., Köllhofer, D., Ehrich, T. H. \& Jefferson, R. A. The ownership question of plant gene and genome intellectual properties. Nat. Biotechnol. 33, 1138-1143 (2015).

41. Baiser, B., Olden, J. D., Record, S., Lockwood, J. L. \& McKinney, M. L. Pattern and process of biotic homogenization in the New Pangaea. Proc. R. Soc. Lond. B 279, 4772-4777 (2012).

42. Carroll, S. P. et al. Applying evolutionary biology to address global challenges. Science 346, 1245993 (2014)

43. Koh, L. P. \& Wilcove, D. S. Is oil palm agriculture really destroying tropical biodiversity? Conserv. Lett. 1, 60-64 (2008)

44. Gómez-González, S., Ojeda, F. \& Fernandes, P. M. Portugal and Chile: longing for sustainable forestry while rising from the ashes. Environ. Sci. Policy 81, 104-107 (2018).

45. Gossner, M. M. et al. Land-use intensification causes multitrophic homogenization of grassland communities. Nature 540, 266-269 (2016).

46. Rodrigues, J. L. M. et al. Conversion of the Amazon rainforest to agriculture results in biotic homogenization of soil bacterial communities. Proc. Natl Acad. Sci. USA 110, 988-993 (2013)

47. Magurran, A. E., Dornelas, M., Moyes, F., Gotelli, N. J. \& McGill, B. Rapid biotic homogenization of marine fish assemblages. Nat. Commun. 6, 8405 (2015).

48. FAOSTAT Statistics Database (FAO, 2017).

49. Khoury, C. K. et al. Increasing homogeneity in global food supplies and the implications for food security. Proc. Natl Acad. Sci. USA 111, 4001-4006 (2014) This paper shows that national portfolios of food supplies have seen increased crop species diversity, whereas globally, they have become more homogeneous in composition.

50. Borras, S. M., Franco, J. C., Isakson, S. R., Levidow, L. \& Vervest, P. The rise of flex crops and commodities: implications for research. J. Peasant Stud. 43, 93-115 (2016).

51. Foley, J. A. et al. Global consequences of land use. Science 309, 570-574 (2005).

52. Fader, M., Gerten, D., Krause, M., Lucht, W. \& Cramer, W. Spatial decoupling of agricultural production and consumption: quantifying dependences of countries on food imports due to domestic land and water constraints. Environ. Res. Lett. 8, 021002 (2013).

53. Clapp, J. Financialization, distance and global food politics. J. Peasant Stud. 41, 797-814 (2014).

A study that provides a new perspective on the increasing role of finance in an intensified global food system and how it weakens feedback effects between production and consumption.

54. Crona, B. I. et al. Masked, diluted and drowned out: how global seafood trade weakens signals from marine ecosystems. Fish Fish. 17, 1175-1182 (2016).

55. Berkes, F. et al. Globalization, roving bandits, and marine resources. Science 311, 1557-1558 (2006).

56. Meyfroidt, P. \& Lambin, E. F. Forest transition in Vietnam and displacement of deforestation abroad. Proc. Natl Acad. Sci. USA 106, 16139-16144 (2009).

57. Srinivasan, U. T. et al. The debt of nations and the distribution of ecological impacts from human activities. Proc. Natl Acad. Sci. USA 105, 1768-1773 (2008).

58. Hoekstra, A. Y. \& Wiedmann, T. O. Humanity's unsustainable environmental footprint. Science 344, 1114-1117 (2014). 
59. Dalin, C., Wada, Y., Kastner, T. \& Puma, M. J. Groundwater depletion embedded in international food trade. Nature 543, 700-704 (2017)

60. Isakson, S. R. Derivatives for development? Small-farmer vulnerability and the financialization of climate risk management. J. Agrar. Change 15, 569-580 (2015).

61. Steneck, R. S. et al. Creation of a gilded trap by the high economic value of the Maine lobster fishery. Conserv. Biol. 25, 904-912 (2011).

62. Hughes, T. P., Carpenter, S., Rockström, J., Scheffer, M. \& Walker, B. Multiscale regime shifts and planetary boundaries. Trends Ecol. Evol. 28, 389-395 (2013).

63. Rocha, J. C., Peterson, G. D. \& Biggs, R. Regime shifts in the anthropocene: drivers, risks, and resilience. PLOS ONE 10, e0134639 (2015).

64. Rocha, J. C., Peterson, G., Bodin, Ö. \& Levin, S. Cascading regime shifts within and across scales. Science 362, 1379-1383 (2018).

65. Steffen, W. et al. Trajectories of the Earth System in the Anthropocene. Proc. Natl Acad. Sci. USA 115, 8252-8259 (2018).

66. van Nes, E. H. \& Scheffer, M. Implications of spatial heterogeneity for catastrophic regime shifts in ecosystems. Ecology 86, 1797-1807 (2005).

67. Thébault, E. \& Fontaine, C. Stability of ecological communities and the architecture of mutualistic and trophic networks. Science 329, 853-856 (2010).

68. Haldane, A. G. \& May, R. M. Systemic risk in banking ecosystems. Nature 469, 351-355 (2011).

69. Bardoscia, M., Battiston, S., Caccioli, F. \& Caldarelli, G. Pathways towards instability in financial networks. Nat. Commun. 8, 14416 (2017)

70. Battiston, S. et al. Complexity theory and financial regulation. Science $\mathbf{3 5 1}, \mathbf{8 1 8 - 8 1 9}$ (2016).

71. Brummitt, C. D., D'Souza, R. M. \& Leicht, E. A. Suppressing cascades of load in interdependent networks. Proc. Natl Acad. Sci. USA 109, E680-E689 (2012).

72. Buldyrev, S. V., Parshani, R., Paul, G., Stanley, H. E. \& Havlin, S. Catastrophic cascade of failures in interdependent networks. Nature 464, 1025-1028 (2010).

73. Donges, J. F., Schultz, H. C. H., Marwan, N., Zou, Y. \& Kurths, J. Investigating the topology of interacting networks. Eur. Phys. J. B 84, 635-651 (2011).

74. Tu, C., Suweis, S. \& D'Odorico, P. Impact of globalization on the resilience and sustainability of natural resources. Nat. Sustain. 2, 283-289 (2019).

This study explores how resilience in a system may either increase or decrease depending on the network structure, and shows that the resilience of the global food trade network has decreased over the past 20 years.

75. Scheffer, M. et al. Anticipating critical transitions. Science 338, 344-348 (2012)

76. Helbing, D. Globally networked risks and how to respond. Nature 497, 51-59 (2013). This work shows how an increasingly complex and networked world paves the way for risks to emerge and interact, while at the same time reducing our ability to understand and manage these risks.

77. Haldane, A. G. Rethinking the financial network https://www.bankofengland.co.uk/ speech/2009/rethinking-the-financial-network (Bank of England, 2009).

78. Elmqvist, T. et al. Response diversity, ecosystem change, and resilience. Front. Ecol. Environ. 1, 488-494 (2003).

79. Grêt-Regamey, A., Huber, S. H. \& Huber, R. Actors' diversity and the resilience of socialecological systems to global change. Nat. Sustain. 2, 290-297 (2019).

80. Cottrell, R. S. et al. Food production shocks across land and sea. Nat. Sustain. 2, 130-137 (2019).

This study shows how the frequency of food production shocks has increased in all major food sectors across land and sea over the past 53 years.

81. Boettiger, C., Ross, N. \& Hastings, A. Early warning signals: The charted and uncharted territories. Theor. Ecol. 6, 255-264 (2013).

82. Carpenter, S. R., Brock, W. A., Folke, C., van Nes, E. H. \& Scheffer, M. Allowing variance may enlarge the safe operating space for exploited ecosystems. Proc. Natl Acad. Sci. USA $112,14384-14389$ (2015).

This paper shows how management of short-term variance increases the risk of crossing critical ecosystem thresholds in the long term, resulting in less desirable ecosystem states.

83. Seidl, R., Rammer, W. \& Spies, T. A. Disturbance legacies increase the resilience of forest ecosystem structure, composition, and functioning. Ecol. Appl. 24, 2063-2077 (2014).

84. Leslie, P. \& McCabe, J. T. Response diversity and resilience in social-ecological systems. Curr. Anthropol. 54, 114-143 (2013).

85. Peters, D. P. C. et al. Cross-scale interactions, nonlinearities, and forecasting catastrophic events. Proc. Natl Acad. Sci. USA 101, 15130-15135 (2004).

86. Stephens, S. L. et al. Temperate and boreal forest mega-fires: Characteristics and challenges. Front. Ecol. Environ. 12, 115-122 (2014).

87. Meyfroidt, P., Rudel, T. K. \& Lambin, E. F. Forest transitions, trade, and the global displacement of land use. Proc. Natl Acad. Sci. USA 107, 20917-20922 (2010).

88. Sartori, M. \& Schiavo, S. Connected we stand: A network perspective on trade and global food security. Food Policy 57, 114-127 (2015).

89. Folke, C. et al. Resilience thinking: Integrating resilience, adaptability and transformability. Ecol. Soc. 15, 20-28 (2010).

90. Homer-Dixon, T. et al. Synchronous failure: The emerging causal architecture of global crisis. Ecol. Soc. 20, 6 (2015).

91. Kearney, J. Food consumption trends and drivers. Philos. Trans. R. Soc. B 365, 2793-2807 (2010).

92. Banse, M., Van Meijl, H., Tabeau, A. \& Woltjer, G. Will EU biofuel policies affect global agricultural markets? Eur. Rev. Agric. Econ. 35, 117-141 (2008).

93. Colbran, $\mathrm{N}$. The financialisation of agricultural commodity futures trading and its impact on the 2006-2008 global food crisis. In 3rd Bienn. Ingram Colloq. Int. Law Dev. Univ. New South Wales 1-13 (2011).

94. Centeno, M. A., Nag, M., Patterson, T. S., Shaver, A. \& Windawi, A. J. The emergence of global systemic risk. Annu. Rev. Sociol. 41, 65-85 (2015).

95. Wood, S. A., Smith, M. R., Fanzo, J., Remans, R. \& DeFries, R. S. Trade and the equitability of global food nutrient distribution. Nat. Sustain. 1, 34-37 (2018).

96. Frank, A. B. et al. Dealing with femtorisks in international relations. Proc. Natl Acad. Sci. USA 111, 17356-17362 (2014)
97. Keys, P. W. et al. Anthropocene risk. Nat. Sustain. 2, 667-673 (2019).

98. Carpenter, S. R. et al. General resilience to cope with extreme events. Sustainability 4 3248-3259 (2012).

99. Kareiva, P., Watts, S., McDonald, R. \& Boucher, T. Domesticated nature: shaping landscapes and ecosystems for human welfare. Science 316, 1866-1869 (2007).

100. Rasmussen, L. V. et al. Social-ecological outcomes of agricultural intensification. Nat. Sustain. 1, 275 (2018).

101. Steffen, W. et al. Planetary boundaries: guiding human development on a changing planet. Science 347, 1259855 (2015)

102. Springmann, M. et al. Options for keeping the food system within environmental limits. Nature 562, 519-525 (2018).

103. Raworth, K. Doughnut economics: seven ways to think like a 21st-century economist. (Chelsea Green Publishing, 2017).

104. O'Neill, D. W., Fanning, A. L., Lamb, W. F. \& Steinberger, J. K. A good life for all within planetary boundaries. Nat. Sustain. 1, 88-95 (2018).

105. Fischer, J. et al. Land sparing versus land sharing: moving forward. Conserv. Lett. 7, 149-157 (2014).

106. Loos, J. et al. Putting meaning back into 'sustainable intensification'. Front. Ecol. Environ. 12, 356-361 (2014)

107. Pretty, J. et al. Global assessment of agricultural system redesign for sustainable intensification. Nat. Sustain. 1, 441 (2018).

108. Renard, D. \& Tilman, D. National food production stabilized by crop diversity. Nature $\mathbf{5 7 1}$, 257-260 (2019).

109. McDermott, M., Mahanty, S. \& Schreckenberg, K. Examining equity: a multidimensional framework for assessing equity in payments for ecosystem services. Environ. Sci. Policy 33, 416-427 (2013)

110. Lubchenco, J., Cerny-Chipman, E. B., Reimer, J. N. \& Levin, S. A. The right incentives enable ocean sustainability successes and provide hope for the future. Proc. Natl Acad. Sci. USA 113, 14507-14514 (2016)

111. Galaz, V., Gars, J., Moberg, F., Nykvist, B. \& Repinski, C. Why ecologists should care about financial markets. Trends Ecol. Evol. 30, 571-580 (2015).

112. Scholtens, B. Why finance should care about ecology. Trends Ecol. Evol. 32, 500-505 (2017).

113. Jouffray, J.-B., Crona, B., Wassénius, E., Bebbington, J. \& Scholtens, B. Leverage points in the financial sector for seafood sustainability. Sci. Adv. 5, eaax3324 (2019).

114. Sumaila, U. R., Lam, V., Le Manach, F., Swartz, W. \& Pauly, D. Global fisheries subsidies: an updated estimate. Mar. Policy 69, 189-193 (2016).

115. Pe'er, G. et al. EU agricultural reform fails on biodiversity. Science 344, 1090-1092 (2014)

116. Central banks and supervisors network for greening the financial system (NGFS). Climate Action in Financial Institutions https://www.mainstreamingclimate.org/ngfs/ (2019).

117. Galaz, V. et al. Tax havens and global environmental degradation. Nat. Ecol. Evol. 2, 1352-1357 (2018).

118. Miller, D. D. et al. Cutting a lifeline to maritime crime: marine insurance and IUU fishing. Front. Ecol. Environ. 14, 357-362 (2016).

119. Gardner, T. A. et al. Transparency and sustainability in global commodity supply chains. World Dev. 121, 163-177 (2019)

120. Spink, J. \& Moyer, D. C. Defining the public health threat of food fraud. J. Food Sci. 76, R157-R163 (2011)

121. Helyar, S. J. et al. Fish product mislabelling: failings of traceability in the production chain and implications for illegal, unreported and unregulated (IUU) fishing. PLOS ONE 9, e98691 (2014).

122. Nakamura, K. et al. Seeing slavery in seafood supply chains. Sci. Adv. 4, e1701833 (2018).

123. Boström, M., Jönsson, A. M., Lockie, S., Mol, A. P. J. \& Oosterveer, P. Sustainable and responsible supply chain governance: challenges and opportunities. J. Clean. Prod. 107, 1-7 (2015).

124. Wognum, P. M., Bremmers, H., Trienekens, J. H., Van Der Vorst, J. G. A. J. \& Bloemhof, J. M. Systems for sustainability and transparency of food supply chains - current status and challenges. Adv. Eng. Inform. 25, 65-76 (2011).

125. Neumann, B. \& Unger, S. From voluntary commitments to ocean sustainability. Science 363, 35-36 (2019).

126. Francisco, K. \& Swanson, D. The supply chain has no clothes: technology adoption of blockchain for supply chain transparency. Logistics 2, 2 (2018).

127. Caro, M. P., Ali, M. S., Vecchio, M. \& Giaffreda, R. Blockchain-based traceability in AgriFood supply chain management: a practical implementation. In 2018 loT Vertical and Topical Summit on Agriculture-Tuscany 1-4 (2018).

128. Hardt, M. J., Flett, K. \& Howell, C. J. Current barriers to large-scale interoperability of traceability technology in the seafood sector. J. Food Sci. 82 (S1), A3-A12 (2017).

129. Kates, R. W. et al. Sustainability science. Science 292, 641-642 (2001).

130. Dauvergne, P. \& Lister, J. Big brand sustainability: governance prospects and environmental limits. Glob. Environ. Change 22, 36-45 (2012).

131. Barbier, E. B., Burgess, J. C. \& Dean, T. J. How to pay for saving biodiversity. Science $\mathbf{3 6 0}$ 486-488 (2018)

132. Österblom, H., Jouffray, J.-B., Folke, C. \& Rockström, J. Emergence of a global sciencebusiness initiative for ocean stewardship. Proc. Natl Acad. Sci. USA 114, 9038-9043 (2017).

133. Arneth, A. et al. Climate Change and Land. An IPCC Special Report on Climate Change Desertification, Land Degradation, Sustainable Land Management, Food Security, and Greenhouse Gas Fluxes in Terrestrial Ecosystems (IPCC, 2019).

134. Westley, F. et al. Tipping toward sustainability: emerging pathways of transformation. Ambio 40, 762-780 (2011).

135. Nyborg, K. et al. Social norms as solutions. Science 354, 42-43 (2016).

136. Lenton, T. M. \& Latour, B. Gaia 2.0. Science 361, 1066-1068 (2018).

137. Jørgensen, P. S. et al. Antibiotic and pesticide susceptibility and the Anthropocene operating space. Nat. Sustain. 1, 632-641 (2018)

138. Heap, I. \& Duke, S. O. Overview of glyphosate-resistant weeds worldwide. Pest Manag Sci. 74, 1040-1049 (2018) 


\section{Perspective}

139. Knuth, S. E. Global finance and the land grab: mapping twenty-first century strategies. Can. J. Dev. Stud. 36, 163-178 (2015).

140. Clapp, J. \& Isakson, S. R. Risky returns: the implications of financialization in the food system. Dev. Change 49, 437-460 (2018).

141. Epstein, G. in Financialization and the World Economy (ed. Epstein, G. A.) 3-16 (2005).

142. Sullivan, S. Banking Nature? The spectacular financialisation of environmental conservation. Antipode 45, 198-217 (2013).

143. Golden, J. S. et al. Making sure the blue economy is green. Nat. Ecol. Evol. 1, 17 (2017)

144. First World Bank 'blue bond' approved for Seychelles. SDG Knowledge Hub https://sdg. iisd.org/news/first-world-bank-blue-bond-approved-for-seychelles/ (2017).

145. Knott, C. \& Neis, B. Privatization, financialization and ocean grabbing in New Brunswick herring fisheries and salmon aquaculture. Mar. Policy 80, 10-18 (2017)

146. Benediktsson, K. \& Karlsdottir, A. Iceland: crisis and regional development-thanks for al the fish? Eur. Urban Reg. Stud. 18, 228-235 (2011).

147. Bodin, Ö. Collaborative environmental governance: achieving collective action in socialecological systems. Science 357, eaan1114 (2017).

148. Epstein, G. et al. Institutional fit and the sustainability of social-ecological systems. Curr. Opin. Environ. Sustain. 14, 34-40 (2015)

149. Bodin, O., Crona, B., Thyresson, M., Golz, A. L. \& Tengö, M. Conservation success as a function of good alignment of social and ecological structures and processes. Conserv. Biol. 28, 1371-1379 (2014)

150. Barnes, M. L. et al. Social-ecological alignment and ecological conditions in coral reefs. Nat. Commun. 10, 2039 (2019).

151. Gelcich, S. et al. Navigating transformations in governance of Chilean marine coastal resources. Proc. Natl Acad. Sci. USA 107, 16794-16799 (2010).
Acknowledgements We thank R. Cottrell for sharing data on global food production shock frequency. We are grateful to Mistra, the Beijer Foundation, the Erling-Persson Family Foundation and the Swedish Government for providing funding. J.-B.J. and P.S.-J. were supported by the Swedish Research Council Formas (project numbers 2015-743 and 2016-00451, respectively).

Author contributions M.N. conceived the original idea. M.N. and J.-B.J. developed the idea and led the writing with support from A.V.N. All authors contributed to the development and writing of the paper.

Competing interests J.-B.J., B.C., P.S.-J. and C.F. provide scientific support to companies in the seafood sector through the Seafood Business for Ocean Stewardship (SeaBOS) initiative (https://keystonedialogues.earth). The other authors declare no competing interests.

\section{Additional information}

Supplementary information is available for this paper at https://doi.org/10.1038/s41586-0191712-3.

Correspondence and requests for materials should be addressed to M.N.

Peer review information Nature thanks Kirsty Lewis, Pablo A. Marquet and the other, anonymous, reviewer(s) for their contribution to the peer review of this work. Reprints and permissions information is available at http://www.nature.com/reprints. Publisher's note Springer Nature remains neutral with regard to jurisdictional claims in published maps and institutional affiliations.

(c) Springer Nature Limited 2019 